Rakenteiden Mekaniikka (Journal of Structural Mechanics)

Vol. 50, No 3, 2017, pp. 279-282

https://rakenteidenmekaniikka.journal.fi/index

https:/doi.org/10.23998/rm.64915

(c)Author(s) 2017.

Open access under CC BY-SA 4.0 license.

\title{
Design approaches for additive manufactured components, with a focus on selective laser melting
}

\author{
Erin Komi ${ }^{1}$ and Petteri Kokkonen
}

Summary. Additive manufacturing (AM) of metal components is characterized by the joining of material particles or feedstock to make parts described by 3D model data in typically a layer by layer fashion. These modern and constantly improving manufacturing techniques inherently allow far more geometric freedom than traditional "subtractive" manufacturing processes, and thus necessitate novel approaches to component design. Careful utilization of this geometric freedom can be translated into products characterized by improved functionality and performance, simplified assemblies, are customizable, and/or lightweight. This paper provides a brief overview design approaches, manufacturing limitations, and available tools for successful design of additive manufactured components, with special attention paid to the selective laser melting (SLM) approach.

Key words: additive manufacturing (AM), selective laser melting (SLM), design, lattice, topology optimization, parts consolidation, process simulation, 3D printing

Received 15 June 2017. Accepted 14 August 2017. Published online 21 August 2017.

\section{Introduction}

With the rapid advances made in metal AM technologies, there is push within industry to explore the economically viable business cases where this manufacturing approach can offer advantages over traditional technologies. The key to identifying these cases relies in part on taking an entirely new approach to design, whereby old manufacturing limitations need to be erased from designers' consciousness and the geometric freedoms offered by AM explored. This paper briefly reviews some of the promising design approaches that have been utilised in realising the potential of AM.

\footnotetext{
${ }^{1}$ Corresponding author. Erin.Komi@vtt.fi
} 


\section{Material minimization}

While there are plenty of cases where lightweight design can lead to cost and energy savings and improved performance (e.g. in aerospace and automotive industries), there are additional benefits for reduction of material usage for components produced by metal AM. These benefits include reduction in manufacturing costs through lower material usage and shorter print times, and potential reduction in the component's distortions and residual stresses. Several tools and techniques have been widely adapted for lightweighting in AM design, including the use of topology, shape and size optimization, and inclusion of lattice structures [2,5-7]. An example of how topology optimization can be used in component design is described in Figure 1, where a hydraulic valve block has been redesigned for Nurmi Cylinders Oy [8]. In this case, the component redesign resulted in a product that weighed $76 \%$ less than the traditionally manufactured part, improved flow of hydraulic fluid through internal channels, and reduced the likelihood of leaks.

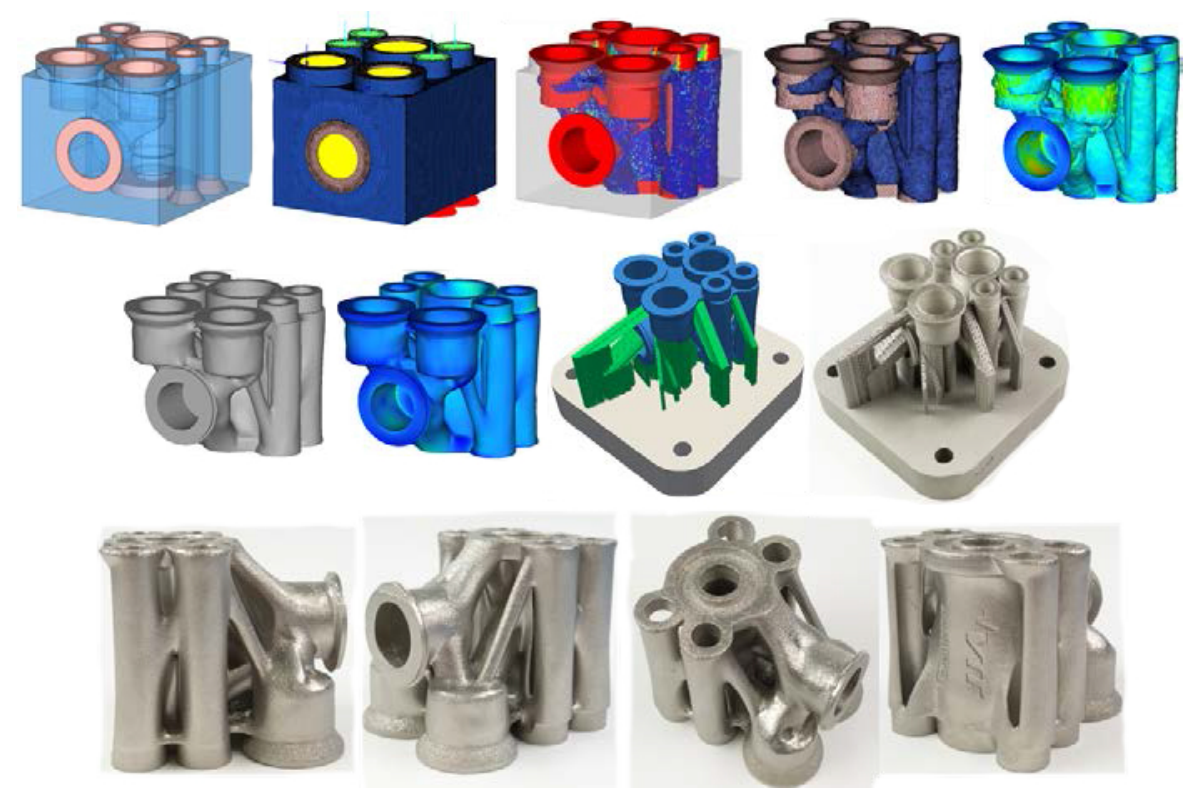

Figure 1. Process for designing a hydraulic valve block specifically for AM, including topology optimization, results interpretation, smoothing of design, design validation, and print preparation [8].

Some examples of lattice structures printed in 316L stainless steel by selective laser melting (SLM) technique can be seen in Figure 2. Well-designed lattice structures are capable of providing same or better stiffness than a 3D topology optimized part while weighing even less. They also have the added benefit of potentially being selfsupporting, which can reduce manufacturing costs during post-processing of a printed component. A case involving a welding head bracket from Meconet Oy is shown in Figure 3, where the part has been redesigned with both topology optimization and lattice structures. Redesign with self-supporting lattice structures is particularly interesting in this case where the topology optimized component required a significant amount of supports for manufacture. 

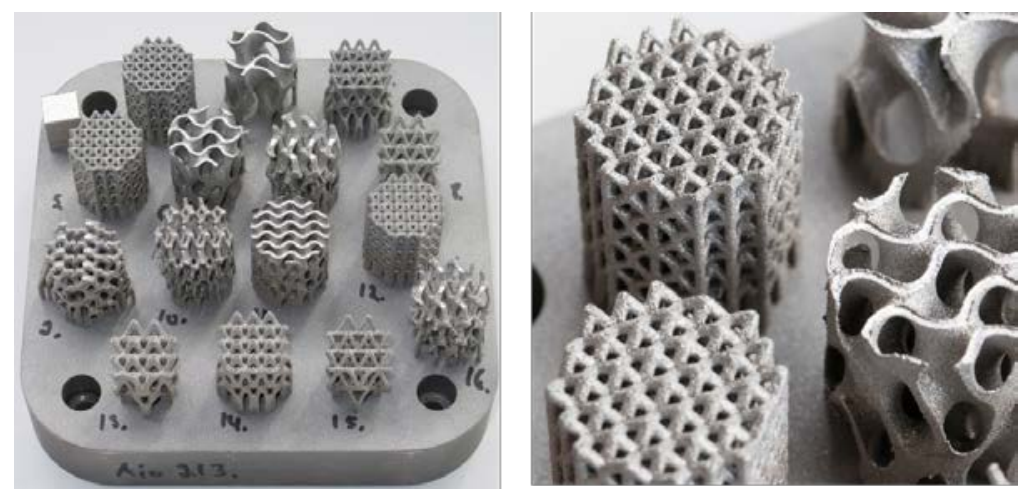

Figure 2. Example lattice and gyroid structures manufactured in 316L stainless steel by selective laser melting technique
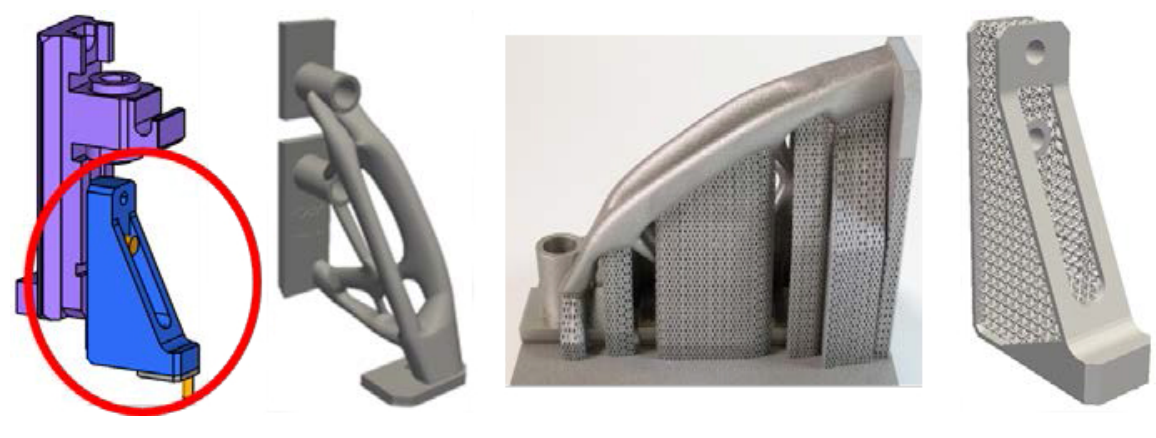

Figure 3. Topology optimization and lattice design of Meconet Oy welding head bracket.

\section{Functionality, performance and parts consolidation}

Another objective in the design for AM is to take advantage of the geometric freedom in order to make gains in terms of new functionalities and improved performance. Some examples of this include the use of internal features such as channels or cavities for optimized fluid flow, improved heat transfer, or integrated electronics and sensors [2]. Additionally, the consolidation of many parts of an assembly into one or a few parts with more complex geometries can lead to reduced manufacturing/assembly costs, with the added bonus that there are fewer spare parts which can be created locally and ondemand [9-10].

Lattice structures have also been used to create locally variable material properties by modifying the relative density of a part and creating site-specific stiffness and yield strength $[2,5,11]$. This has also been taken one step further to include creation of printed lattice preforms to reinforce cast metal components [12].

\section{Conclusion}

While it is acknowledged that there are manufacturing limitations to be considered when creating a component by SLM or similar AM technologies [13], the geometric freedom of design that is unleashed by these processes must be explored. Systematic, 
simulation-based design coupled with workflows that include AM process simulation and an understanding of the manufacturing limitations can help to guarantee successful creation of metal components that are functionally superior, lightweight, highperformance, and requiring little-to-no assembly and minimal machining and finishing.

\section{References}

[1] Additive manufacturing - General principles - Terminology, ISO/ASTM 52900:2015, 2017.

[2] M.K. Thompson, et al. Design for Additive Manufacturing: Trends, opportunities, considerations, and constraints, CIRP Annals - Manufacturing Technology, 6:737-760, 2016.

[3] W. Gao, et al. The status, challenges, and future of additive manufacturing in engineering, Computer-Aided Design, 69:65-89, 2015. https://doi.org/10.1016/j.cad.2015.04.001

[4] C. Emmelmann, D. Herzon, and J. Kranz. "Design for laser additive manufacturing” in Laser Additive Manufacturing, M. Brandt Ed. Woodhead, pp. 259-279, 2017. https://doi.org/10.1016/B978-0-08-100433-3.00010-5

[5] B.H. Jared, et al. Additive manufacturing: Toward holistic design, Scripta Materialia, 135:141-147, 2017. https://doi.org/10.1016/j.scriptamat.2017.02.029

[6] T. Primo, et al. Additive manufacturing integration with topology optimization methodology for innovative product design, The International Journal of Advanced Manufacturing Technology, 2017. doi:10.1007/s00170-017-0112-9. https://doi.org/10.1007/s00170-017-0112-9

[7] Y. Saadlaoui. Topology optimization and additive manufacturing: Comparison of conception methods using industrial codes, Journal of Manufacturing Systems, 43:1:178186. https://doi.org/10.1016/j.jmsy.2017.03.006

[8] E. Komi. Design for additive manufacturing, VTT-R-03159-16, VTT, 2016.

[9] Y. Tang, S. Yang, and Y.F. Zhao. "Sustainable design for additive manufacturing through functionality integration and part consolidation" in Handbook of

Sustainability in Additive Manufacturing, S.S. Muthu and M.M Savalani, Ed. Springer, Hong Kong, pp. 101-141, 2016. https://doi.org/10.1007/978-981-10-0549-7_6

[10] Yang, S., Tang, Y., Zhao, Y.F. A new part consolidation method to embrace the design freedom of additive manufacturing, Journal of Manufacturing Processes, 20: 444-449, 2015. https://doi.org/10.1016/j.jmapro.2015.06.024

[11] S. Tammas-Williams and I. Todd. Design for additive manufacturing with site-specific properties in metals and alloys, Scripta Materialia, 135:105-110. https://doi.org/10.1016/j.scriptamat.2016.10.030

[12] A.E. Pawlowski, et al. Damage-tolerant metallic composites via melt infiltration of additively manufactured preforms, Materials \& Design, 125:346-351, 2017. https://doi.org/10.1016/j.matdes.2017.04.072

[13] P. Kokkonen, et al. Design guide for additive manufacturing of metal components by SLM process, VTT-R-02160-16, VTT, 2016.

Erin Komi, Petteri Kokkonen

VTT Technical Research Centre of Finland Ltd

P.O. Box 1000, FI-02044 VTT, Finland

Erin.Komi@vtt.fi, Petteri.Kokkonen@vtt.fi 